Article

\title{
Alcohol Drinking by Husbands/Partners Is Associated with Higher Intimate Partner Violence against Women in Angola
}

\author{
Sanni Yaya *(D) and Bishwajit Ghose *(D) \\ Faculty of Social Sciences, School of International Development and Global Studies, University of Ottawa, \\ Ottawa, ON K1N6N5, Canada \\ * Correspondence: Sanni.yaya@uottawa.ca (S.Y.); brammaputram@gmail.com (B.G.)
}

Received: 5 December 2018; Accepted: 15 January 2019; Published: 22 January 2019

\begin{abstract}
Intimate partner violence (IPV), as the most prevalent form of violence against women, is a commonly encountered phenomenon across sub-Saharan African countries, including Angola. As a fast-growing economy, Angola is experiencing a booming alcohol industry and persistent IPV and women's rights issues, along with weak prohibition and enforcement against this practice. However, so far, there is no systematic research investigating the predictors of IPV in Angola and whether spousal alcohol drinking has any relationship with women's experience of IPV. Therefore, in this study, we aimed to assess the predictors of IPV (defined as physical, emotional, and sexual violence) among Angolan women with a special focus on their partners' alcohol drinking habit. Cross-sectional data on 7669 women aged 15-49 years from the Angola Demographic and Health Survey were used for this study. Data were analyzed using descriptive and logistic regression methods. Results indicated that physical IPV $(32.3 \%, 95 \%$ Confidence Interval $=30.3$ to 34.5$)$ was most prevalent, followed by emotional $(27.3 \%, 95 \% \mathrm{CI}=25.3$ to 29.4$)$ and sexual IPV $(7.4 \%, 95 \% \mathrm{CI}=6.6$ to 8.4$)$. In the multivariate analysis, higher education and household wealth status showed protective effects against certain forms of IPV. Alcohol drinking by husbands/partners was associated with significantly higher odds of experiencing physical [OR $=2.950 ; 95 \% \mathrm{CI}=2.632,3.306]$, emotional [OR $=2.470 ; 95 \% \mathrm{CI}$ $=2.187,2.789]$, and sexual IPV [OR $=2.729 ; 95 \% \mathrm{CI}=2.220,3.354]$ among women. Women who reported experiencing physical IPV had increased odds of drinking alcohol [OR $=1.474 ; 95 \% \mathrm{CI}=$ $1.290,1.684$ ] compared with those who did not. These findings reflect the widespread prevalence of IPV in sub-Saharan African countries. Special focus should be given to married men with alcohol drinking habits to reduce women's vulnerability to IPV and dependence on alcohol use.
\end{abstract}

Keywords: Angola; alcohol drinking; intimate partner violence; women's health

\section{Introduction}

Although historically regarded as a familial issue, IPV has been gaining increasing attention from human rights, health, and social researchers, especially since the Declaration on the Elimination of Violence against Women by United Nations General Assembly in 1993. Violence against women (VAW) is a global phenomenon but is known to be particularly widespread across sub-Saharan Africa (SSA), where it is considered as a major public health, social, and human development challenge at large [1-5]. $\mathrm{IPV}$, which is the most common form of VAW, affects millions of women irrespective of geography, age, sociocultural background, and sexual orientation [2,6]. According to a UN-HABITAT report, (State of the World's Cities, 2006-2007), violence makes up at least $25 \%-30 \%$ of urban crime, including IPV, with the prevalence being twice as high in the developing countries [7]. Intuitively, persistent exposure to torturous and violent behavior by an intimate partner can force a woman to escape from 
home, resulting in homelessness, economic insecurity, and substance abuse [8-11], which themselves are strong risk factors for abduction, harassment, sexual assault, and socioeconomic marginalization. As such, IPV can have serious repercussions on women's livelihood and economic security, safety, health, and overall well-being [12-15]. Despite this, there is currently no research evidence on IPV in many countries in SSA, including Angola.

To date, a substantial volume of empirical research has been dedicated to exploring the determinants of IPV in SSA. A majority of the studies have interpreted the factors associated with IPV from various demographic, environmental, sociocultural, economic, and interpersonal relational perspectives [1,16-20]. In recent years, a growing number of studies have shown the role of substance abuse, such as problem drinking, on abusive behavior [21-25]. Alcohol drinking is not a predominant cause of IPV, and neither is IPV unknown among men who do not drink. The mechanism through which alcohol use, especially hazardous drinking, can trigger violent behavior is via its role in reducing self-control and increasing proneness to aggression, especially within conjugal relationships [26-28]. There are no country-representative studies on alcohol drinking habit among Angolan men, but some reports maintain that Angola ranks among the top alcohol drinkers in Africa [29]. As the country still struggles to recover from the social disorders left by decades of civil war, the high dependence on alcohol and the occurrence of IPV are supposed be widely prevalent as well due to their overlapping sociopolitical mechanisms.

In the current literature, not much is known regarding the alcohol-IPV relationship in Angola, especially on a nationally representative sample. In addition, most of the past research on substance abuse defined IPV in terms of physical violence, with relatively less attention on other equally important types of violence, including emotional and sexual violence. To this end, we undertook the present study based on recent data from the Angola Demographic and Health Survey (ADHS 2015-2016). The survey, which was nationally representative, interviewed married women aged 15-49 years to collect information on a range of demographic, health, and IPV-related topics. In view of the lack of research evidence on IPV in Angola, we used this open-access data with the objectives of investigating the prevalence and sociocultural predictors of IPV. We also explored the relationship between experiencing IPV and alcohol drinking among women. As we were interested in IPV perpetrated by husbands/partners, we analyzed data only on married women and with a special focus on partners' characteristics, including education and alcohol drinking habits.

\section{Methods}

\subsection{Data Source}

This study was based on the Angola Demographic and Health Survey (DHS) conducted in 2015-2016. This is the first standard DHS survey that was conducted in Angola as part of the National Development Strategy Program as well as the Millennium Development Goals. The survey was conducted and coordinated by Instituto Nacional de Estatística in collaboration with the Ministry of Health (Ministério da Saúde or MINSA), along with technical assistance from UNICEF and ICF International through the Demographic and Health Surveys Program and the World Health Organization. The survey collected data on a nationally representative sample, including both urban and rural areas, on a range of demographic and health indicators, such as maternal healthcare use status, fertility, and child mortality rates. For sample selection, a multistage sampling technique was employed involving the systematic selection of clusters at the national level, and the final selection of households from those clusters for survey. Data collection took place from October 2015 to March 2016. In total, 14,975 women were finally interviewed, generating a response rate of $96 \%$. However, the sample population selected for the domestic violence questionnaire was smaller $(n=7669)$ than the entire sample. Details of the survey are available at Instituto Nacional de Estatística (INE), Ministério da Saúde (MINSA), Ministério do Planeamento e do Desenvolvimento Territorial (MINPLAN) e 
ICF. 2017. Inquérito de Indicadores Múltiplos e de Saúde em Angola 2015-2016. Luanda, Angola e Rockville, Maryland, EUA: INE, MINSA, MINPLAN e ICF.

\subsection{Measures}

The outcome measure was self-reported experience of abusive behavior/actions perpetrated by husband/partner. The Angola Demographic and Health Survey included a range of questions pertinent to physical, emotional, and sexual assaults. These single-item questions are widely used in assessing self-reported experience of IPV. The following eight items were used for assessing physical abuse: Have you (1) ever been pushed/shook/thrown something; (2) ever been slapped; (3) ever been punched/hit by something; (4) ever been kicked; (5) ever had arm twisted; (6) ever had bruise because of husband's actions, (7) ever had injuries, sprains, dislocation, burns; and (8) ever had wound, broken bones. Emotional abuse was assessed by the following questions: Have you (1) ever been humiliated by husband/partner; (2) ever been threatened with harm by husband/partner; (3) ever been insulted or made to feel bad by husband/partner; and (4) ever experienced any other emotional violence. For sexual abuse, the following two questions were asked: Have you (1) ever forced into unwanted sex and (2) ever experienced other unwanted sexual acts. The answers were categorized as "Yes" if the respondents had ever experienced the given situation and "No" if they have not.

A set of sociodemographic and economic predictor variables were included in the analysis based on their conceptual association with experience of abusive behavior. This was facilitated by a review of the existing literature in other countries in sub-Saharan Africa, including the Democratic Republic of Congo [30], Ethiopia [31], Ghana [32], and Nigeria [33]. The underlying theme that emerged from the review was that women's susceptibility to IPV generally results from low empowerment, such as lower socioeconomic status, as well as behavioral factors embedded in the sociocultural environment, such as ethnic norms, religious guidelines, power relationship in the household (head, wife), and risk factors of abusive behavior (alcohol drinking). In light of this understanding, and depending on availability from the survey dataset, the following were included in the analysis: age groups (15-19/20-24/25-29/30-34/35-39/40-44/45-49); residency (urban/rural); education (no education/completed primary education/completed secondary education/completed higher education); occupation (unemployed/white collar/blue collar); drinks alcohol (no/yes); household head's sex (male/female); wealth status (poorest/richest); husband/partner's education (none/primary/secondary/higher); husband/partner's occupation (unemployed/white collar/blue collar); husband/partner drinks alcohol (no/yes); age difference ( $0-5$ years / $6-10$ years / $>10$ years). Description of these variables is provided in Table 1.

Table 1. Sample characteristics. $(n=7669)$.

\begin{tabular}{|c|c|c|c|}
\hline Variables & Description & $\mathbf{n}$ & $\%$ \\
\hline \multicolumn{4}{|l|}{ Age groups } \\
\hline $15-19$ & \multirow{7}{*}{ Age of the respondent in the interview year } & 619 & 8.1 \\
\hline $20-24$ & & 1613 & 21.0 \\
\hline $25-29$ & & 1713 & 22.3 \\
\hline $30-34$ & & 1323 & 17.3 \\
\hline $35-39$ & & 1036 & 13.5 \\
\hline $40-44$ & & 817 & 10.7 \\
\hline $45-49$ & & 548 & 7.1 \\
\hline \multicolumn{4}{|l|}{ Residency } \\
\hline Urban & \multirow{2}{*}{ Whether the respondent is a rural or urban resident } & 4343 & 56.6 \\
\hline Rural & & 3326 & 43.4 \\
\hline \multicolumn{4}{|l|}{ Education } \\
\hline No Education & \multirow{4}{*}{ Highest level of formal education attained by the respondent } & 2612 & 34.1 \\
\hline Complete Primary & & 2896 & 37.8 \\
\hline Complete Secondary & & 1965 & 25.6 \\
\hline Higher & & 196 & 2.6 \\
\hline
\end{tabular}


Table 1. Cont.

\begin{tabular}{|c|c|c|c|}
\hline Variables & Description & $\mathbf{n}$ & $\%$ \\
\hline \multicolumn{4}{|l|}{ Occupation } \\
\hline Unemployed & \multirow{3}{*}{$\begin{array}{l}\text { White collar jobs referred to professional, service, skilled } \\
\text { employments. Blue collar included agriculture, clerk, sales, } \\
\text { and unskilled employments. }\end{array}$} & 2046 & 26.7 \\
\hline White collar & & 2580 & 33.6 \\
\hline Blue collar & & 3043 & 39.7 \\
\hline \multicolumn{4}{|l|}{ Drinks alcohol } \\
\hline No & \multirow{2}{*}{ Self-reported drinking habit of the respondent } & 5917 & 77.2 \\
\hline Yes & & 1752 & 22.8 \\
\hline \multicolumn{4}{|l|}{ Household head's sex } \\
\hline Male & \multirow{2}{*}{$\begin{array}{c}\text { Sex of the person responsible for managing the household } \\
\text { and making key decisions }\end{array}$} & 5226 & 68.1 \\
\hline Female & & 2443 & 31.9 \\
\hline Household wealth quintile & \multirow{6}{*}{$\begin{array}{l}\text { Index of relative wealth status of households based on the } \\
\text { possession of durable goods (e.g., refrigerator and TV) and } \\
\text { building material (e.g., concrete and wooden), rather than } \\
\text { personal income [34]. Q1 represents the lowest and Q5 the } \\
\text { highest wealth quintile. }\end{array}$} & & \\
\hline Poorest (Q1) & & 2914 & 20.27 \\
\hline Poorer (Q2) & & 3367 & 23.42 \\
\hline Middle (Q3) & & 3412 & 23.73 \\
\hline Richer (Q4) & & 2526 & 17.57 \\
\hline Richest (Q5) & & 2160 & 15.02 \\
\hline \multicolumn{4}{|l|}{ Husband/partner's education } \\
\hline No Education & \multirow{4}{*}{ Highest level of formal education attained by the respondent } & 1111 & 16.7 \\
\hline Primary & & 1788 & 26.9 \\
\hline Secondary & & 2746 & 41.3 \\
\hline Higher & & 1002 & 15.1 \\
\hline \multicolumn{4}{|l|}{ Husband/partner's occupation } \\
\hline Unemployed & \multirow{3}{*}{$\begin{array}{l}\text { White collar jobs referred to professional, service, skilled } \\
\text { employments. Blue collar included agriculture, clerk, sales, } \\
\text { and unskilled employments. }\end{array}$} & 574 & 8.6 \\
\hline White collar & & 2911 & 43.8 \\
\hline Blue collar & & 3162 & 47.6 \\
\hline \multicolumn{4}{|c|}{ Husband/partner's drinks alcohol } \\
\hline No & \multirow{2}{*}{$\begin{array}{l}\text { Self-reported drinking habit of the respondent's } \\
\text { husband/partner }\end{array}$} & 4636 & 60.5 \\
\hline Yes & & 3033 & 39.5 \\
\hline \multicolumn{4}{|l|}{ Age difference with spouse } \\
\hline $0-5$ years & \multirow{3}{*}{$\begin{array}{l}\text { Absolute age difference between respondent and } \\
\text { respondent's husband/partner }\end{array}$} & 3445 & 51.8 \\
\hline $6-10$ years & & 1825 & 27.5 \\
\hline$>10$ years & & 1377 & 20.7 \\
\hline
\end{tabular}

\subsection{Analytical Procedure}

All analyses were carried out using StataCorp 14, Texas, USA. The dataset was first scanned for outliers and missing values. Participants who were not selected for the domestic violence module were removed from the analysis. As the survey used cluster survey design, we used the survey design method for all analyses to account for the sampling strata, primary sampling unit, and sampling weight provided in the dataset.

We also ran collinearity tests to check for multicollinearity issues. Only women's alcohol drinking was found to be significantly correlated with age and educational status. At the first step of the analysis, we presented the basic sociodemographic characteristics of the participants in terms of frequencies and percentages. Following that, the prevalence of three different types of IPV (physical, emotional, and sexual) and their individual components were presented as percentages and $95 \%$ CIs. At the last step, we conducted multivariate logistic regression to measure the odds of association between the types of IPV and the sociodemographic predictors. To facilitate the selection of the suitable variables, we carried out chi-squared bivariate tests to check which variables were associated with the outcome measures at a significance level of $25 \%$. These were not shown in the results. All the variables met this criterion and were retained for final regression models. Women's alcohol drinking was not included in the regression analysis due to multicollinearity issues. 
In total, four models were run: one for experiencing each of the three individual types of IPV and another for experiencing any IPV. Next, we ran four additional regression models to calculate the association between women's alcohol drinking (as outcome measure) and three types of IPV plus any IPV. The four models were designed to adjust the analysis for the sociodemographic variables in certain combinations. The results of regression analysis were presented as odds ratios along with their $95 \%$ CIs. A $p$-value of $<0.05$ was considered statistically significant for all regression models.

\subsection{Ethical Approval}

All participants gave informed consent prior to taking part in the interviews. Data were openaccess and available online in anonymized form; therefore, no additional approval was necessary.

\section{Results}

\subsection{Descriptive Analysis}

In total, 7669 women were included in the analysis. The mean age was 27.65 years (Standard Deviation 9.25), with a greater proportion aged below 30 years. The basic sociodemographic characteristics of the participants are presented in Table 1.

\subsection{Prevalence of IPV}

The prevalence of three different types of IPV is presented in Table 2. About one-third of the women reported experiencing any physical IPV $(32.3 \%, 95 \% \mathrm{CI}=30.3$ to 34.5$)$, more than a quarter reported any emotional IPV $(27.3 \%, 95 \% \mathrm{CI}=25.3$ to 29.4$)$, and less than one-tenth reported sexual IPV $(7.4 \%, 95 \% \mathrm{CI}=6.6$ to 8.4$)$. Overall, more than two-fifth of the women reported experiencing any IPV $(41.1 \%, 95 \% \mathrm{CI}=38.7$ to 43.6$)$.

Table 2. Prevalence of different forms of intimate partner violence (IPV).

\begin{tabular}{ccc}
\hline Physical IPV & Never & Often/Sometimes \\
\hline Pushed/shook/thrown something & $88.5(87.4,89.6)$ & $11.5(10.4,12.6)$ \\
Slap & $70.5(68.5,72.4)$ & $29.5(27.6,31.5)$ \\
Punch/hit by something & $88.6(87.4,89.7)$ & $11.4(10.3,12.6)$ \\
Kick & $89.1(88.0,90.2)$ & $10.9(9.8,12.0)$ \\
Arm twisted & $90.1(89.0,91.2)$ & $9.9(8.8,11.0)$ \\
Ever had bruise because of husband/partner's actions & $69.8(66.8,72.6)$ & $30.2(27.4,33.2)$ \\
Injuries, sprains, dislocation, burns & $79.8(77.0,82.2)$ & $20.2(17.8,23.0)$ \\
Wound, broken bones & $89.6(87.4,91.4)$ & $10.4(8.6,12.6)$ \\
Any physical IPV & $67.7(65.5,69.7)$ & $32.3(30.3,34.5)$ \\
\hline Emotional IPV & & \\
Ever humiliated & & \\
Threatened with harm & $84.2(82.7,85.5)$ & $15.8(14.5,17.3)$ \\
Insulted/made feel bad & $92.6(91.6,93.5)$ & $7.4(6.5,8.4)$ \\
Other emotional violence & $78.8(76.7,80.7)$ & $21.2(19.3,23.3)$ \\
Any emotional IPV & $72.7(70.6,74.7)$ & $27.3(25.3,29.4)$ \\
Sexual IPV & $72.7(70.6,4.7)$ & $27.3(25.3,29.4)$ \\
\hline Forced into unwanted sex & & \\
Other unwanted sexual acts & & $6.7(5.9,7.5)$ \\
Any sexual IPV & $93.3(92.5,94.1)$ & $3.0(2.5,3.7)$ \\
Any IPV & $97.0(96.3,97.5)$ & $7.4(6.6,8.4)$ \\
\hline
\end{tabular}

\subsection{Multivariable Analysis}

Predictors of experiencing IPV are presented in Table 3. The results revealed that age was not associated with sexual IPV, with women in the higher age groups (e.g., 30-34 years) having relatively 
lowers odds compared with those in the lowest age group (15-19 years). Women in the rural areas had significantly lower odds of reporting all three types of IPV. Women with higher education were less likely to experience IPV compared with those with no education (except for those in the highest education category). Women in the higher wealth quintile households in general had lower odds of experiencing physical and sexual IPV. The odds of physical IPV in the highest wealth quintile was 0.696 times $[95 \% \mathrm{CI}=0.510,0.950]$ lower compared with those in the lowest quintile. Women engaged in blue collar profession had 1.182 times $[95 \% \mathrm{CI}=1.029,1.358]$ higher odds of experiencing any form of IPV. The odds of experiencing physical IPV was lower for the female-headed households [OR = $0.832,95 \% \mathrm{CI}=0.723,0.958]$. Regarding husband/partner's characteristics, having primary level education was associated with higher odds of physical and emotional IPV. Husband/partner's blueand white-collar professions were associated with higher odds of sexual and emotional IPV. Alcohol drinking was significantly associated with higher odds of physical $[\mathrm{OR}=2.950 ; 95 \% \mathrm{CI}=2.632,3.306]$, emotional $[\mathrm{OR}=2.470 ; 95 \% \mathrm{CI}=2.187,2.789]$ and sexual $[\mathrm{OR}=2.729 ; 95 \% \mathrm{CI}=2.220,3.354] \mathrm{IPV}$. Having an age gap of 6-10 years showed a protective effect against experiencing IPV [OR $=0.848$, $95 \% \mathrm{CI}=0.746,0.965]$.

Table 3. Predictors of different forms of IPV. Angola Demographic and Health Survey (ADHS) 2015.

\begin{tabular}{|c|c|c|c|c|}
\hline \multirow{2}{*}{ Variables } & Physical & Emotional & Sexual & Any IPV \\
\hline & IPV & IPV & IPV & \\
\hline \multicolumn{5}{|l|}{ Age (15-19) } \\
\hline $20-24$ & $\begin{array}{c}1.115 \\
(0.894,1.390)\end{array}$ & $\begin{array}{c}1.212 \\
(0.948,1.548)\end{array}$ & $\begin{array}{c}1.280 \\
(0.869,1.884)\end{array}$ & $\begin{array}{c}1.259 \\
(0.919,1.555)\end{array}$ \\
\hline $25-29$ & $\begin{array}{c}0.956 \\
(0.764,1.198)\end{array}$ & $\begin{array}{c}1.238 \\
(0.966,1.586)\end{array}$ & $\begin{array}{c}1.085 \\
(0.729,1.614)\end{array}$ & $\begin{array}{c}1.138 \\
(0.918,1.410)\end{array}$ \\
\hline $30-34$ & $\begin{array}{c}0.903 \\
(0.712,1.145)\end{array}$ & $\begin{array}{c}1.047 \\
(0.806,1.361)\end{array}$ & $\begin{array}{c}0.825 \\
(0.537,1.267)\end{array}$ & $\begin{array}{c}0.947 \\
(0.754,1.188)\end{array}$ \\
\hline $35-39$ & $\begin{array}{c}0.820 \\
(0.639,1.052)\end{array}$ & $\begin{array}{c}0.971 \\
(0.738,1.277)\end{array}$ & $\begin{array}{c}0.571 * \\
(0.354,0.919)\end{array}$ & $\begin{array}{c}0.891 \\
(0.703,1.130)\end{array}$ \\
\hline $40-44$ & $\begin{array}{c}0.842 \\
(0.647,1.095)\end{array}$ & $\begin{array}{c}1.019 \\
(0.764,1.359)\end{array}$ & $\begin{array}{c}0.604 * \\
(0.365,0.997)\end{array}$ & $\begin{array}{c}0.911 \\
(0.709,1.171)\end{array}$ \\
\hline $45-49$ & $\begin{array}{c}0.924 \\
(0.688,1.242)\end{array}$ & $\begin{array}{c}1.023 \\
(0.739,1.414)\end{array}$ & $\begin{array}{c}0.613 \\
(0.344,1.094)\end{array}$ & $\begin{array}{c}0.983 \\
(0.741,1.305)\end{array}$ \\
\hline \multicolumn{5}{|l|}{ Residency (Urban) } \\
\hline Rural & $\begin{array}{c}0.745^{* * *} \\
(0.630,0.882)\end{array}$ & $\begin{array}{c}0.711^{* * *} \\
(0.593,0.854)\end{array}$ & $\begin{array}{c}0.665^{* *} \\
(0.495,0.894)\end{array}$ & $\begin{array}{c}0.781^{* *} \\
(0.665,0.918)\end{array}$ \\
\hline \multicolumn{5}{|l|}{ Education (None) } \\
\hline Complete Primary & $\begin{array}{c}0.714 \text { * } \\
(0.548,0.930)\end{array}$ & $\begin{array}{c}0.767 \\
(0.574,1.025)\end{array}$ & $\begin{array}{c}0.725 \\
(0.443,1.186)\end{array}$ & $\begin{array}{c}0.683 * * \\
(0.530,0.881)\end{array}$ \\
\hline Complete secondary & $\begin{array}{c}0.742^{* *} \\
(0.610,0.904)\end{array}$ & $\begin{array}{c}0.961 \\
(0.779,1.186)\end{array}$ & $\begin{array}{c}1.073 \\
(0.765,1.507)\end{array}$ & $\begin{array}{c}0.782 * \\
(0.648,0.944)\end{array}$ \\
\hline Secondary & $\begin{array}{c}0.558^{* * *} \\
(0.407,0.764)\end{array}$ & $\begin{array}{c}0.804 \\
(0.580,1.114)\end{array}$ & $\begin{array}{c}0.612 \\
(0.326,1.147)\end{array}$ & $\begin{array}{c}0.625^{* *} \\
(0.467,0.838)\end{array}$ \\
\hline Higher & $\begin{array}{c}0.652 \\
(0.420,1.014)\end{array}$ & $\begin{array}{c}0.976 \\
(0.625,1.522)\end{array}$ & $\begin{array}{c}0.863 \\
(0.373,1.996)\end{array}$ & $\begin{array}{c}0.789 \\
(0.525,1.186)\end{array}$ \\
\hline \multicolumn{5}{|l|}{ Wealth quintile (Q1) } \\
\hline Poorer & $\begin{array}{c}0.967 \\
(0.817,1.144)\end{array}$ & $\begin{array}{c}0.886 \\
(0.738,1.063)\end{array}$ & $\begin{array}{c}1.061 \\
(0.781,1.442)\end{array}$ & $\begin{array}{c}0.920 \\
(0.784,1.080)\end{array}$ \\
\hline Middle & $\begin{array}{c}0.924 \\
(0.739,1.156)\end{array}$ & $\begin{array}{c}0.768^{*} \\
(0.603,0.979)\end{array}$ & $\begin{array}{c}0.747 \\
(0.500,1.116)\end{array}$ & $\begin{array}{c}0.878 \\
(0.708,1.087)\end{array}$ \\
\hline Richer & $\begin{array}{c}0.862 \\
(0.662,1.122)\end{array}$ & $\begin{array}{c}0.683 \text { ** } \\
(0.514,0.908)\end{array}$ & $\begin{array}{c}0.675 \\
(0.423,1.077)\end{array}$ & $\begin{array}{c}0.856 \\
(0.665,1.103)\end{array}$ \\
\hline Richest (Q5) & $\begin{array}{c}0.696^{*} \\
(0.510,0.950)\end{array}$ & $\begin{array}{c}0.782 \\
(0.564,1.084)\end{array}$ & $\begin{array}{c}0.584 \\
(0.333,1.024)\end{array}$ & $\begin{array}{c}0.835 \\
(0.622,1.121)\end{array}$ \\
\hline
\end{tabular}


Table 3. Cont.

\begin{tabular}{|c|c|c|c|c|}
\hline \multirow{2}{*}{ Variables } & Physical & Emotional & Sexual & Any IPV \\
\hline & IPV & IPV & IPV & \\
\hline \multicolumn{5}{|l|}{ Occupation (None) } \\
\hline Blue-collar & $\begin{array}{c}1.110 \\
(0.960,1.283)\end{array}$ & $\begin{array}{c}1.151 \\
(0.986,1.343)\end{array}$ & $\begin{array}{c}1.133 \\
(0.879,1.460)\end{array}$ & $\begin{array}{c}1.182 * \\
(1.029,1.358)\end{array}$ \\
\hline White-collar & $\begin{array}{c}0.969 \\
(0.819,1.146)\end{array}$ & $\begin{array}{c}1.030 \\
(0.859,1.236)\end{array}$ & $\begin{array}{c}1.016 \\
(0.753,1.370)\end{array}$ & $\begin{array}{c}1.011 \\
(0.861,1.187)\end{array}$ \\
\hline \multicolumn{5}{|c|}{ Household head's sex (Male) } \\
\hline Female & $\begin{array}{c}0.832 * \\
(0.723,0.958)\end{array}$ & $\begin{array}{c}0.864 \\
(0.743,1.005)\end{array}$ & $\begin{array}{c}0.916 \\
(0.712,1.179)\end{array}$ & $\begin{array}{c}0.856 * \\
(0.749,0.978)\end{array}$ \\
\hline \multicolumn{5}{|c|}{ Husband/Partner's characteristics } \\
\hline \multicolumn{5}{|l|}{ Education (None) } \\
\hline Complete Primary & $\begin{array}{c}1.333^{* *} \\
(1.111,1.600)\end{array}$ & $\begin{array}{c}1.452^{* * *} \\
(1.190,1.772)\end{array}$ & $\begin{array}{c}1.104 \\
(0.796,1.532)\end{array}$ & $\begin{array}{c}1.490 * * * \\
(1.251,1.774)\end{array}$ \\
\hline Complete secondary & $\begin{array}{c}1.209 \\
(0.994,1.471)\end{array}$ & $\begin{array}{c}1.227 \\
(0.990,1.521)\end{array}$ & $\begin{array}{c}0.968 \\
(0.681,1.375)\end{array}$ & $\begin{array}{c}1.259 * \\
(1.044,1.518)\end{array}$ \\
\hline Secondary & $\begin{array}{c}1.083 \\
(0.768,1.527)\end{array}$ & $\begin{array}{c}1.046 \\
(0.729,1.501)\end{array}$ & $\begin{array}{c}0.721 \\
(0.373,1.396)\end{array}$ & $\begin{array}{c}1.091 \\
(0.791,1.504)\end{array}$ \\
\hline Higher & $\begin{array}{c}1.046 \\
(0.825,1.325)\end{array}$ & $\begin{array}{c}0.987 \\
(0.758,1.285)\end{array}$ & $\begin{array}{c}1.133 \\
(0.750,1.710)\end{array}$ & $\begin{array}{c}1.025 \\
(0.817,1.286)\end{array}$ \\
\hline \multicolumn{5}{|l|}{ Occupation (None) } \\
\hline Blue-collar & $\begin{array}{c}1.171 \\
(0.949,1.446)\end{array}$ & $\begin{array}{c}1.742^{* * *} \\
(1.363,2.227)\end{array}$ & $\begin{array}{c}1.834^{* *} \\
(1.194,2.815)\end{array}$ & $\begin{array}{c}1.345^{* *} \\
(1.098,1.647)\end{array}$ \\
\hline White-collar & $\begin{array}{c}1.162 \\
(0.933,1.447)\end{array}$ & $\begin{array}{c}1.579 * * * \\
(1.223,2.039)\end{array}$ & $\begin{array}{c}1.601 * \\
(1.025,2.500)\end{array}$ & $\begin{array}{c}1.265 * \\
(1.024,1.561)\end{array}$ \\
\hline \multicolumn{5}{|l|}{ Drinks alcohol (No) } \\
\hline Yes & $\begin{array}{c}2.950 * * * \\
(2.632,3.306)\end{array}$ & $\begin{array}{c}2.470 * * * \\
(2.187,2.789)\end{array}$ & $\begin{array}{c}2.729 * * * \\
(2.220,3.354)\end{array}$ & $\begin{array}{c}2.942 * * * \\
(2.637,3.283) \\
\end{array}$ \\
\hline \multicolumn{5}{|c|}{$\begin{array}{l}\text { Age difference with spouse } \\
\text { ( } 0-5 \text { years })\end{array}$} \\
\hline $6-10$ & $\begin{array}{c}0.848^{*} \\
(0.746,0.965)\end{array}$ & $\begin{array}{c}0.959 \\
(0.836,1.099)\end{array}$ & $\begin{array}{c}0.895 \\
(0.710,1.127)\end{array}$ & $\begin{array}{c}0.908 \\
(0.803,1.026)\end{array}$ \\
\hline$>10$ & $\begin{array}{c}0.912 \\
(0.789,1.055)\end{array}$ & $\begin{array}{c}0.973 \\
(0.832,1.138)\end{array}$ & $\begin{array}{c}1.042 \\
(0.805,1.348)\end{array}$ & $\begin{array}{c}0.923 \\
(0.803,1.060)\end{array}$ \\
\hline$N$ & 6647 & 6647 & 6647 & 6647 \\
\hline
\end{tabular}

Exponentiated coefficients; $95 \%$ confidence intervals in brackets. ${ }^{*} p<0.05,{ }^{* *} p<0.01,{ }^{* * *} p<0.001$.

We ran four additional models to investigate whether or not women who reported experiencing IPV were more or less likely to report drinking alcohol (Table 4). At first, we ran univariate models without adjusting for any covariate and found that only physical IPV was associated with significantly higher odds of drinking alcohol $[\mathrm{OR}=1.810,95 \% \mathrm{CI}=1.447,2.264]$. This association slightly diminished on progressive adjustment for the individual and husband/partner's characteristics but remained statistically significant. Apart from physical IPV, experiencing any IPV also increased the odds of alcohol [OR $=1.341,95 \% \mathrm{CI}=1.177,1.529]$.

Model 1 = univariate, Model $2=$ Model $1+$ women's characteristics, Model $3=$ husband $/$ partner's characteristics, Model $4=$ women's characteristics + husband $/$ partner's characteristics + age difference. 
Table 4. Odds of women's alcohol drinking habit in relation to experiencing any IPV. Angola DHS 2015.

\begin{tabular}{|c|c|c|c|c|}
\hline Type of IPV & Model 1 & Model 2 & Model 3 & Model 4 \\
\hline \multicolumn{5}{|l|}{ Physical (No) } \\
\hline Yes & $\begin{array}{c}1.810 * * * \\
(1.447,2.264)\end{array}$ & $\begin{array}{c}1.444 * * \\
(1.117,1.867)\end{array}$ & $\begin{array}{c}1.827^{* * * *} \\
(1.456,2.293)\end{array}$ & $\begin{array}{c}1.474^{* * *} \\
(1.290,1.684)\end{array}$ \\
\hline \multicolumn{5}{|l|}{ Emotional (No) } \\
\hline Yes & $\begin{array}{c}1.112 \\
(0.940,1.315)\end{array}$ & $\begin{array}{c}0.967 \\
(0.797,1.172)\end{array}$ & $\begin{array}{c}1.078 \\
(0.909,1.277)\end{array}$ & $\begin{array}{c}1.128 \\
(0.978,1.300)\end{array}$ \\
\hline \multicolumn{5}{|l|}{ Sexual (No) } \\
\hline Yes & $\begin{array}{c}1.017 \\
(0.831,1.245)\end{array}$ & $\begin{array}{c}0.942 \\
(0.745,1.192)\end{array}$ & $\begin{array}{c}1.082 \\
(0.882,1.329)\end{array}$ & $\begin{array}{c}1.185 \\
(0.943,1.491)\end{array}$ \\
\hline \multicolumn{5}{|l|}{ Any IPV (No) } \\
\hline Yes & $\begin{array}{c}1.045 \\
(0.805,1.357)\end{array}$ & $\begin{array}{c}0.995 \\
(0.738,1.343)\end{array}$ & $\begin{array}{c}1.054 \\
(0.809,1.374)\end{array}$ & $\begin{array}{c}1.341^{* * *} \\
(1.177,1.529)\end{array}$ \\
\hline
\end{tabular}

Exponentiated coefficients; $95 \%$ confidence intervals in brackets. ${ }^{*} p<0.05,{ }^{* *} p<0.01,{ }^{* * *} p<0.001$.

\section{Discussion}

Physical or sexual violence affects more than one-third of all women globally, with adverse physical and psychosocial consequences in the long run [35]. Women experiencing IPV are more prone to injury, depression, unintended pregnancy, and sexually transmitted infections and are almost twice as likely as other women to be alcohol abusers [35]. As such, IPV is a particular concern for women's health in low-income settings because of the inadequate health infrastructure and underappreciation of women's health issues, such as in Angola. In the current study, more than $40 \%$ of the women reported experiencing some form of IPV, with more than one-third reporting some form of physical violence. This is higher than previous reports from Malawi (13\%-20\%) [36], Kenya (37\%) [18], South Africa (>20\%) [1], and Uganda (36.6\%) [37]. However, a Nigerian subnational study among civil servants found a far higher prevalence during the last 12 months (66\%) [38]. The large cross-country differences may be explained by the contextual sociocultural factors and by methodological heterogeneity. In this study, we included a generous set of indicators that can be considered as violent actions and behaviors with adverse effects on women's physical and mental health, which might well be the reason behind the higher prevalence of IPV than in most countries for which data are available.

IPV is generally defined as a multifaceted issue with diverse aetiological factors and embedded predominantly into the sociocultural value system determining women's susceptibility to violence and aggression. Sociocultural factors are by far the most commonly cited issues associated with higher degrees of exposure to IPV $[17,26,38]$. A review of the current literature suggests that the central mechanism through which these factors affect IPV is their impact on women's socioeconomic empowerment. From this perspective, our findings are in line with the existing evidence base. We observed that women with higher educational status generally had lower odds of reporting physical IPV. Higher household wealth status showed an inverse association with sexual IPV, indicating potentially higher sexual autonomy among women in the more well-off households. Surprisingly, women's occupational status did not show any noticeable effect on their experience of IPV but that of their husband/partner did. In general, husband/partner's higher education (completed primary) and better occupational status showed a positive association with IPV. This finding is counterintuitive in the sense that higher socioeconomic status (SES) among husbands/partners has no protective effect on committing spousal violence. This might be indicative of the fact that higher socioeconomic disparity between spouses can increase the likelihood of experiencing IPV. Women in rural areas were less likely to report any form of IPV; this is perhaps linked to lower awareness of the issue and socioeconomic position, which leads to greater acceptance of, or favorable attitude to abusive behavior. 
Apart from the socioeconomic factors, the findings also suggest that husband/partner's alcohol drinking can significantly increase the odds of experiencing all forms of IPV. In fact, the strength of the association was highest for husband/partner's alcohol drinking among all the predictor variables. Intuitively, discordant drinking habits can increase relationship stress, decrease marital satisfaction, and increase perpetration of abusive actions [39-41]. Immoderate drinking behavior can lead to increased risk and severity of abusive behavior and initiation and escalation of intimate partner violence (IPV) [42]. These theories are supported by previous multicountry studies in sub-Saharan Africa that found a robust association between husband/partner's alcohol drinking and occurrence of IPV.

A subnational study in South Africa found that about two-third (65\%) of the women experiencing spousal abuse reported that their partner was drunk prior to the abusive actions [43]. However, the present findings need to be interpreted with caution as we had no information regarding the level of drinking. Our findings also indicate that women who report physical IPV are more likely to use alcohol than those who do not. The use of alcohol as a destressing mechanism is well known in the medical literature. Experiencing IPV is both physically and psychologically stressful, which in turn increases the likelihood of alcohol consumption as a general coping strategy [44]. Moreover, stressful events evoke thoughts about alcohol and enhances the rewarding effects among those who use it to cope with the negative circumstances [45]. Currently, not much is known about the prevalence of alcohol use in Angola. Therefore, it is suggested that health and social policy-makers take steps to control alcohol consumption as a strategy to reduce the burden of IPV. More studies should be carried out by including the sociocultural predictors of alcohol use and its relationship to IPV in the population.

This is the first study to report the prevalence and predictors of IPV against women in Angola. The data were of good quality and extracted from a nationally representative survey. We applied rigorous methodological and analytical standards and interpreted the findings from two important perspectives: women's empowerment and husband/partner's alcohol drinking behavior. The findings can be of critical importance for taking evidence-based steps to address IPV and focusing on women's empowerment programs in the country. Apart from its important contributions, our study has several important limitations. Firstly, the variables were self-reported and thus remain subject to reporting bias. Secondly, the survey was cross-sectional, hence the associations do not indicate any causal relationship. In addition, the association between husband/partner's alcohol drinking and IPV should be interpreted in light of the fact that we were unable to measure the level of drinking. In many societies, some degree of drinking is acceptable depending on the local context and may not result in loss of self-control to the point that can trigger abusive behavior. Moreover, abusive behavior can be determined to a great extent by the quality of relationship influenced by a variety of complex issues, such as marital satisfaction and household issues that are not necessarily associated with drinking behavior. Future studies should focus on exploring the relational nuances that may explain the mechanism between husband/partner's drinking habit and women's experience of IPV.

\section{Conclusions}

More than two-third of women aged 15-49 in Angola reported experiencing some form of IPV. Regarding women's characteristics, being residents of rural areas and having higher education were associated with lower likelihood of reporting IPV. Based on this finding, it is suggested that women living in urban areas and lacking schooling experience be given special attention by women's human rights and empowerment programs in an effort to address IPV in Angola. Although the results cannot confirm any causality, it is assumed that husband/partner's alcohol drinking significantly increases the likelihood of IPV. Women reporting IPV were also more likely to use alcohol compared with those who did not. More studies are necessary to investigate the cultural norms that tend to normalize IPV, as well as the dynamics of how alcohol drinking among men contributes to this harmful social practice, in order to design effective intervention approaches. Future studies should also focus on assessing 
qualitatively whether the amount of alcohol consumed (e.g., social vs. problem drinking) makes any difference in women's experience of IPV.

Author Contributions: Conceptualisation and data acquisition B.G., Analysis: S.Y., B.G.; Interpretation and supervision: S.Y., B.G.; Manuscript writing: B.G.; Final Validation: S.Y., B.G.

Funding: Self-Funded by Bishwajit Ghose.

Acknowledgments: Authors acknowledge the generous provision of the dataset by DHS that made this study possible.

Conflicts of Interest: The authors declare no conflict of interest.

\section{Abbreviations}

ADHS 2015 Angola Demographic and Health Survey

SSA sub-Saharan Africa

IPV intimate partner violence

VAW violence against women

\section{References}

1. Groves, A.K.; Moodley, D.; McNaughton-Reyes, L.; Martin, S.L.; Foshee, V.; Maman, S. Prevalence and rates of intimate partner violence among South African women during pregnancy and the postpartum period. Mater. Child Health J. 2015, 19, 487-495. [CrossRef]

2. Stark, L.; Asghar, K.; Yu, G.; Bora, C.; Baysa, A.A.; Falb, K.L. Prevalence and associated risk factors of violence against conflict-affected female adolescents: A multi-country, cross-sectional study. J. Glob. Health 2017. [CrossRef]

3. Adedini, S.A.; Odimegwu, C.; Bamiwuye, O.; Fadeyibi, O.; de Wet, N. Barriers to accessing health care in Nigeria: Implications for child survival. Glob. Health Act. 2014, 7. [CrossRef]

4. Garcia-Moreno, C.; Watts, C. Violence against women: An urgent public health priority. Bull. World Health Organ. 2011, 89, 2. [CrossRef]

5. Dalal, S.; Johnson, C.; Fonner, V.; Kennedy, C.E.; Siegfried, N.; Figueroa, C.; Baggaley, R. Improving HIV test uptake and case finding with assisted partner notification services. AIDS 2017, 31, 1867-1876. [CrossRef]

6. Chibber, K.S.; Krishnan, S. Confronting intimate partner violence, a global health care priotity. Mt. Sin. J. Med. 2011, 78, 449-457. [CrossRef]

7. UN-HABITAT. Gender I Women's Safety and Security in Cities. Available online: http:/ / mirror.unhabitat. org $/$ content.asp?typeid $=19 \&$ catid $=303 \&$ cid $=6849$ (accessed on 20 November 2018).

8. Eisenman, D.P.; Richardson, E.; Sumner, L.A.; Ahmad, S.R.; Liu, H.; Valentine, J.; Rodriguez, M.A. Intimate Partner Violence and Community Service Needs among Pregnant and Post-partum Latina Women. Viol. Vict. 2009, 24, 111-121. [CrossRef]

9. Nyamathi, A.; Marfisee, M.; Zhang, S.; Hall, E.; Farabee, D.; Marfisee, M.; Khalilifard, F.; Faucette, M.; Leake, B. Correlates of Serious Violent Crime for Recently Released Parolees with a History of Homelessness. Viol. Vict. 2012, 27, 793-810. [CrossRef]

10. Gerassi, L. From Exploitation to Industry: Definitions, Risks, and Consequences of Domestic Sexual Exploitation and Sex Work Among Women and Girls. J. Hum. Behav. Soc. Environ. 2015, 25, 591-605. [CrossRef]

11. Montesanti, S.R.; Thurston, W.E. Mapping the role of structural and interpersonal violence in the lives of women: Implications for public health interventions and policy. BMC Womens Health 2015, 15. [CrossRef]

12. Antai, D.; Adaji, S. Community-level influences on women's experience of intimate partner violence and terminated pregnancy in Nigeria: A multilevel analysis. BMC Preg. Child. 2012, 12, 128. [CrossRef]

13. Colombini, M.; Dockerty, C.; Mayhew, S.H. Barriers and Facilitators to Integrating Health Service Responses to Intimate Partner Violence in Low- and Middle-Income Countries: A Comparative Health Systems and Service Analysis. Stud. Fam. Plan. 2017, 48, 179-200. [CrossRef]

14. Joyner, K.; Mash, R.J. The value of intervening for intimate partner violence in South African primary care: Project evaluation. BMJ Open 2011, 1. [CrossRef] 
15. Medie, P.A. Women and Postconflict Security: A Study of Police Response to Domestic Violence in Liberia. Politics Gender 2015, 11, 478-498. [CrossRef]

16. Gibbs, A.; Carpenter, B.; Crankshaw, T.; Hannass-Hancock, J.; Smit, J.; Tomlinson, M.; Butler, L. Prevalence and factors associated with recent intimate partner violence and relationships between disability and depression in post-partum women in one clinic in eThekwini Municipality, South Africa. PLoS ONE 2017, 12. [CrossRef]

17. Shamu, S.; Abrahams, N.; Temmerman, M.; Musekiwa, A.; Zarowsky, C. A Systematic Review of African Studies on Intimate Partner Violence against Pregnant Women: Prevalence and Risk Factors. PLoS ONE 2011, 6. [CrossRef]

18. Makayoto, L.A.; Omolo, J.; Kamweya, A.M.; Harder, V.S.; Mutai, J. Prevalence and Associated Factors of Intimate Partner Violence Among Pregnant Women Attending Kisumu District Hospital, Kenya. Mater. Child Health J. 2013, 17, 441-447. [CrossRef]

19. Alangea, D.O.; Addo-Lartey, A.A.; Sikweyiya, Y.; Chirwa, E.D.; Coker-Appiah, D.; Jewkes, R.; Adanu, R.A.K. Prevalence and risk factors of intimate partner violence among women in four districts of the central region of Ghana: Baseline findings from a cluster randomised controlled trial. PLoS ONE 2018, 13, e0200874. [CrossRef]

20. Andarge, E.; Shiferaw, Y. Disparities in Intimate Partner Violence among Currently Married Women from Food Secure and Insecure Urban Households in South Ethiopia: A Community Based Comparative Cross-Sectional Study. Biomed. Res. Int. 2018, 2018. [CrossRef]

21. Klostermann, K.C. Substance abuse and intimate partner violence: Treatment considerations. Subst. Abuse Treat. Prev. Policy 2006, 1, 24. [CrossRef]

22. Chermack, S.T.; Murray, R.L.; Winters, J.J.; Walton, M.A.; Booth, B.M.; Blow, F.C. Treatment Needs of Men and Women with Violence Problems in Substance Use Disorder Treatment. Subst. Use Misuse 2009, 44, 1236-1262. [CrossRef] [PubMed]

23. Golinelli, D.; Longshore, D.; Wenzel, S.L. Substance Use and Intimate Partner Violence: Clarifying the Relevance of Women's Use and Partners' Use. J. Behav. Health Serv. Res. 2009, 36, 199-211. [CrossRef] [PubMed]

24. Martin, S.L.; Beaumont, J.L.; Kupper, L.L. Substance use before and during pregnancy: Links to intimate partner violence. Am. J. Drug Alcohol. Abuse 2003, 29, 599-617. [CrossRef] [PubMed]

25. Moore, B.C.; Easton, C.J.; McMahon, T.J. Drug Abuse and Intimate Partner Violence: A Comparative Study of Opioid-Dependent Fathers. Am. J. Orthopsychiatry 2011, 81, 218-227. [CrossRef] [PubMed]

26. Wilson, I.M.; Graham, K.; Taft, A. Alcohol interventions, alcohol policy and intimate partner violence: A systematic review. BMC Public Health 2014, 14. [CrossRef]

27. Vieira, L.B.; Cortes, L.F.; de Mello Padoin, S.M.; de Oliveira Souza, I.E.; de Paula, C.C.; Terra, M.G. Abuse of alcohol and drugs and violence against women: Experience reports. Rev. Bras. Enferm. 2014, 67, 366-372. [CrossRef] [PubMed]

28. Lim, S.S.; Vos, T.; Flaxman, A.D.; Danaei, G.; Shibuya, K.; Adair-Rohani, H.; AlMazroa, M.A.; Amann, M.; Anderson, R.; Andrews, K.G.; et al. A comparative risk assessment of burden of disease and injury attributable to 67 risk factors and risk factor clusters in 21 regions, 1990-2010: A systematic analysis for the Global Burden of Disease Study 2010. Lancet 2012, 380, 2224-2260. [CrossRef]

29. Mikva, K. 17 Top Alcohol-Drinking Countries in Africa. Moguldom. 2015. Available online: https:// moguldom.com/28638/17-top-alcohol-drinking-countries-in-africa/ (accessed on 23 November 2018).

30. Peterman, A.; Palermo, T.; Bredenkamp, C. Estimates and Determinants of Sexual Violence Against Women in the Democratic Republic of Congo. Am. J. Public Health 2011, 101, 1060-1067. [CrossRef]

31. Fekadu, E.; Yigzaw, G.; Gelaye, K.A.; Ayele, T.A.; Minwuye, T.; Geneta, T.; Teshome, D.F. Prevalence of domestic violence and associated factors among pregnant women attending antenatal care service at University of Gondar Referral Hospital, Northwest Ethiopia. BMC Womens Health 2018, 18. [CrossRef]

32. Owusu Adjah, E.S.; Agbemafle, I. Determinants of domestic violence against women in Ghana. BMC Public Health 2016, 16. [CrossRef]

33. Bishwajit, G.; Yaya, S. Domestic violence: A hidden barrier to contraceptive use among women in Nigeria. Open Access J. Contracept. 2018, 9, 21-28. [CrossRef]

34. Bishwajit, G. Household wealth status and overweight and obesity among adult women in Bangladesh and Nepal. Obes. Sci. Pract. 2017, 3, 185-192. [CrossRef] [PubMed] 
35. WHO I Violence against Women: A 'Global Health Problem of Epidemic Proportions'. Available online: https: //www.who.int/mediacentre/news/releases/2013/violence_against_women_20130620/en/(accessed on 3 December 2018).

36. Bazargan-Hejazi, S.; Medeiros, S.; Mohammadi, R.; Lin, J.; Dalal, K. Patterns of Intimate Partner Violence: A study of female victims in Malawi. J. Injury Viol. Res. 2013, 5, 38-50. [CrossRef]

37. Osinde, M.O.; Kaye, D.K.; Kakaire, O. Intimate partner violence among women with HIV infection in rural Uganda: Critical implications for policy and practice. BMC Womens Health 2011, 11, 50. [CrossRef] [PubMed]

38. Adejimi, A.A.; Fawole, O.I.; Sekoni, O.O.; Kyriacou, D.N. Prevalence and Correlates of Intimate Partner Violence among Male Civil Servants in Ibadan, Nigeria. Afr. J. Med. Sci. 2014, 43, 51-60.

39. Leadley, K.; Clark, C.L.; Caetano, R. Couples' drinking patterns, intimate partner violence, and alcohol-related partnership problems. J. Subst. Abuse 2000, 11, 253-263. [CrossRef]

40. Homish, G.G.; Leonard, K.E. Marital quality and congruent drinking. J. Stud. Alcohol. 2005, 66, 488-496. [CrossRef] [PubMed]

41. Homish, G.G.; Leonard, K.E. The drinking partnership and marital satisfaction: The longitudinal influence of discrepant drinking. J. Consult. Clin. Psychol. 2007, 75, 43-51. [CrossRef]

42. Wilson, I.M.; Graham, K.; Taft, A. Living the cycle of drinking and violence: A qualitative study of women's experience of alcohol-related intimate partner violence: Alcohol-related intimate partner violence. Drug Alcohol. Rev. 2017, 36, 115-124. [CrossRef]

43. O'Connor, M.J.; Tomlinson, M.; LeRoux, I.M.; Stewart, J.; Greco, E.; Rotheram-Borus, M.J. Predictors of Alcohol Use Prior to Pregnancy Recognition among Township Women in Cape Town, South Africa. Soc. Sci. Med. 2011, 72, 83-90. [CrossRef]

44. Keyes, K.; Hatzenbuehler, M.; Grant, B.F.; Hasin, D.S. Stress and Alcohol. Alcohol. Res. 2012, 34, $391-400$. [PubMed]

45. Thomas, S.E.; Merrill, J.E.; von Hofe, J.; Magid, V. Coping Motives for Drinking Affect Stress Reactivity but Not Alcohol Consumption in a Clinical Laboratory Setting. J. Stud. Alcohol. Drugs 2014, 75, 115-123. [CrossRef] [PubMed] 